\title{
MENJADIKAN MATA KULIAH PENDIDIKAN PANCASILA SEBAGAI MEDIA PENANAMAN NILAI-NILAI BELA NEGARA
}

\author{
${ }^{1}$ Wiwin Anggita Sari dan ${ }^{2}$ Bukman Lian \\ ${ }^{1}$ Staf Bagian Kesejahteraan Rakyat Setda Kota Palembang \\ ${ }^{2}$ Universitas PGRI Palembang \\ e-mail : wiwinanggita06@gmail.com
}

\begin{abstract}
National defense is not only to maintain the unity of the Republic of Indonesia, but it must be realized in real life to create critical, loyality, and determination of the nation. This study aimed at finding out the efforts to build the value of defending nation through the Education of Pancasila in Universitas PGRI Palembang. The method used was qualitative case study. The techniques used for collecting data were interview, documentation, observation and literature review. The data collection, data reduction, data presentation, and conclusions were analyzed simultaneously and interactively by using qualitative analysis. The result of this research stated that (1) the students of Universitas PGRI Palembang still had limited knowledge about the values of nation defense, (2) the students did not have critical attitude towards the problems around them, (3) the students had low achievement in motivation. The efforts done by Universitas PGRI Palembang in handling with these problems were fostering: (1) the values of love of the nation (2) fostering the value of national and state awareness, (3) fostering the values of Pancasila as the ideology of the nation, 4) the value of loyalty to the nation, (5) the knowledge of nation defense, and (6) the spirit of achievement as a reflection of the love of the nation.
\end{abstract}

Keywords: Nation Defense, Education of Pancasila, Universitas PGRI Palembang

PENDAHULUAN

Di era globalisasi saat ini, komunikasi logo atribut PKI di kamar kost Mahasiswa dan teknologi berkembang pesat khususnya yang baru baru ini terjadi dan menjadi sumber media elekronik yang dapat mempengaruhi keresahan dan sangat mengancam ideologi sikap dan tindakan generasi muda yang bangsa (Gredinant, 2017).

cenderung tidak sesuai dengan kepribadian

Selain itu, kurangnya sikap motivasi bangsa Indonesia. Munculnya fenomena yang tinggi mahasiswa dalam mengerjakan dapat mengancam ideologi Negara saat ini sesuatu, kurang ingin melakukan kegiatan sudah terlihat dimana seorang Putri Indonesia yang menambah kompetensi, kurang 2015 Anindya Kusuma salah satu lulusan bersemangat, kurang berorganisasi, kurang Universitas di Semarang Jawa Tengah berprestasi, kurang empati terhadap kegiatan menggunakan kaos palu-arit, Artis penyanyi sosial dan kurang kreatif merupakan dangdut Zaskia Gotik (tanpa mengenyam cerminan dari rendahnya pengetahuan pendidikan di Perguruan Tinggi) yang mahasiswa dalam memahami dan melecehkan Pancasila, Pemasangan gambar mengimplementasikan nilai nilai bela Negara 
dalam kehidupan sehari hari (Noor, 2016). dengan sikap bela Negara mulai memudar, Akhir-akhir ini menurut Kristiawan (2016) menjadi seakan-akan bela Negara hanya dengan kemutakhiran teknologi informasi dan merupakan beban tugas militer. komputer sekarang ini, juga banyak terjadi Perkembangan sosial yang begitu cepat karakter negatif di kalangan mahasiswa, menyebabkan sikap rasa cinta tanah air, jiwa antara lain: (1) menulis tugas makalah hanya patriotisme dan nasionalisme menjadi mengunduh dari internet; (2) mereplikasi berkurang. Unsur-unsur bela Negara kurang skripsi hasil karya orang lain; (3) menjawab terimplementasikan dalam kehidupan soal ujian dengan bantuan HP yang dapat masyarakat Indonesia. Kaum muda semakin tersambung dengan internet. banyak yang kurang faham dan kurang

Fenomena di atas, sedikit menjiwai terhadap permasalahan bela Negara. menggambarkan pudarnya rasa Nasionalisme Oleh karena itu, bela Negara merupakan dan semangat berprestasi generasi muda saat tekad, sikap dan perilaku seluruh warga ini yang tentu sangat membahayakan Negara yang dijiwai oleh rasa kecintaan ketahanan Negara. Sebagaimana yang kepada NKRI yang berdasarkan Pancasila dikemukakan oleh Friedman (2009) bahwa dan UUD 1945.

kekuatan ekonomi Negara ditentukan oleh Dalam Undang-Undang No. 3 Tahun kekuatan pertahanan Negara. Oleh karena itu, 2001 Pasal 5, menegaskan bahwa pertahanan sangat penting dan mendesak untuk Negara berfungsi untuk mewujudkan dan melakukan kajian terhadap upaya penanaman mempertahankan seluruh wilayah Negara nilai nilai bela Negara di lingkungan Kesatuan Republik Indonesia sebagai satu Perguruan Tinggi, baik kajian teori, maupun kesatuan wilayah dan menjadi tanggung pelaksanaannya. jawab segenap bangsa. Berdasarkan

Saat ini, masih ada persepsi bahwa ketentuan tersebut maka keikutsertaan bela Negara adalah tugas TNI dan POLRI. segenap warga Negara dalam upaya bela Padahal, upaya pembelaan Negara merupakan Negara dengan sikap cinta tanah air, hak dan kewajiban seluruh warga Negara memegang teguh ideologi bangsa yaitu dengan tingkat kewajiban yang berbeda Pancasila, dan menjunjung tinggi kepentingan sesuai dengan kedudukan dan tugasnya Negara. Sebagaimana yang dikemukakan masing-masing. Sebagaimana yang di oleh Wardana (2009), indikator perilaku bela ungkapkan oleh Hadi, Suryo, Sudarsono Negara adalah: (1) mencintai tanah air, (1) (2014), rasa nasionalisme yang diwujudkan kesadaran berbangsa dan bernegara, (3) yakin 
akan Pancasila sebagai ideologi Negara, (4) pantai terpanjang ke-1 di dunia (setelah rela berkorban untuk bangsa dan Negara, dan Kanada), yaitu sepanjang $95.181 \mathrm{~km}$. Secara (5) memiliki kemampuan awal bela Negara. geografis, Indonesia berada pada silang dunia Indonesia sebagai salah satu Negara yang sangat strategis, yaitu terletak diantara dengan bentang wilayah laut mencapai 5,8 dua benua (Asia dan Australia) dan dua juta km1, dengan gugusan lebih dari 17.500 samudera (Hindia dan Pasifik), dimana pulau, serta garis pantai sepanjang $81.000 \mathrm{~km}$ keduanya merupakan kawasan paling dinamis yang notabene terpanjang ke dua di dunia dalam percaturan dunia, baik secara ekonomis setelah Kanada, merupakan wilayah yang maupun politik. Oleh karena letaknya sangat memenuhi syarat untuk diperebutkan. Belum strategis baik dalam hubungan global maupun lagi luasan areal hutan yang mencapai 99.6 regional tentunya memiliki keuntungan dan juta hektar, merupakan potensi vegetasi yang kerawanan ditinjau dari berbagai sangat besar sepanjang tahun yang akan kepentingan. Kerawanan yang mungkin menjadi arena persaingan kepentingan dihadapi dapat berupa ancaman, gangguan, nasional berbagai Negara. Untuk itu, hambatan dan tantangan baik dari dalam diperlukan langkah antisipasi dan persiapan negeri maupun luar negeri, sehingga hal ini yang matang agar bangsa Indonesia mampu menjadi tantangan bagi penyelenggara menjamin tetap tegaknya keutuhan dan pertahanan Negara (Mahifal, 2016).

kedaulatan Negara Kesatuan Republik Oleh karena itu, pemerintah melalui Indonesia berdasarkan Pancasila dan Undang- salah satu kebijakan program yang konseptual Undang Dasar 1945 (Nurmantyo, dalam dan strategis untuk menanamkan nilai-nilai Gredinant, 2017). peningkatan kesadaran dalam bela Negara Dari sumber lain mengemukakan melalui kegiatan formal yaitu Pendidikan bahwa Indonesia memiliki lebih kurang Pendahuluan Bela Negara (PPBN), 17.480 buah pulau dan menjadikannya Perwujudan Pendidikan Pendahuluan Bela sebagai Negara kepulauan terbesar di dunia Negara (PPBN) yang dicanangkan yang memiliki potensi dan kekayaan alam Pemerintah sebelum dilaksanakan berlimpah. Luas wilayah Indonesia mencapai pembentukan program bela Negara pada lebih kurang 7,7 juta km1, dimana 1/3 dari tanggal 19 Oktober 2015 yang dibuka oleh luasan tersebut merupakan wilayah perairan, Presiden Jokowi. Pemerintah telah sehingga tidaklah mengherankan bilamana menyiapkan Pendidikan Pendahuluan Bela Indonesia merupakan Negara dengan garis Negara melalui program TNI AD yang 
berkerjasama dengan Perguruan Tinggi melalui instruksi Kepala Staf Angkatan Darat bukan hanya sebatas mempertahankan (Kasad) Jenderal Gatot Nurmantyo pada saat ketahanan Negara dengan angkat senjata, pelaksanaan Apel Dansat Satuan Tempur dan tetapi harus diartikan lebih luas, yaitu Satbanpur (Satuan Non Kowil) Tgl 1 s.d 7 membela Negara dalam berbagai hal September 2014 (Gredinant, 2017). disesuaikan dengan kemampuan dan profesi

Perguruan Tinggi sebagai lembaga masing-masing. Ikut mengharumkan nama pendidikan yang memiliki peran sentral untuk bangsa melalui prestasi dalam berbagai menanamkan nilai nilai bela Negara, dimana bidang juga termasuk bela Negara. Sebagai kondisi pergeseran ancaman maupun mana yang dikemukakan oleh Anshoriy dkk tantangan bagi Indonesia saat ini begitu (2008) bahwa dalam upaya menuju nyata. Sebagai lembaga pendidikan, masyarakat madani yang bermartabat dan Perguruan Tinggi harus dapat mempersiapkan modern diperlukan transformasi social generasi penerus yang memiliki ketangguhan. budaya, sebagai prasyarat untuk mendorong Adapun generasi penerus terbaik itu tidak lain proses kemerdekaan dan pembebasan bangsa adalah para mahasiswa yang sangat terbuka yang sangat mendasar. Artinya Pendidikan terhadap ragam disiplin ilmu. Jangan sampai bela Negara akan mendorong setiap individu keterbukaan informasi dan disiplin ilmu tanpa khususnya mahasiswa untuk berjuang dengan penjagaan yang kuat dapat berpotensi sikap dan tindakan nyata melalui peningkatan mengalami krisis dan pembelokan arah yang kompetensi sehingga mampu menjaga dan tidak mudah untuk dikembalikan dan dapat melestarikan sosial budaya bangsa. Dengan pula berbalik menjadi ancaman nyata. Salah demikian, pertahanan Negara pada satu upaya yang dapat dilakukan oleh hakikatnya adalah segala upaya pertahanan Perguruan Tinggi dalam upaya pembentukan yang bersifat semesta, yang karakter sikap bela Negara adalah melalui penyelenggaraannya didasarkan pada kegiatan penanaman nilai nilai bela Negara kesadaran akan hak dan kewajiban seluruh melalui Pendidikan Pancasila di Perguruan warga Negara serta keyakinan akan kekuatan Tinggi, dengan tujuan menumbuhkan sendiri untuk mempertahankan kelangsungan kesadaran kepada mahasiswa bahwa upaya hidup bangsa dan Negara Indonesia yang bela Negara merupakan tugas dan merdeka dan berdaulat (survival of the nation tanggungjawab segenap warga Negara. Ketahanan, 2016). 
Di kemukakan oleh Anwar (2011) kuliah Pendidikan Pancasila yang salah satu bahwa pendidikan bela Negara dapat terlihat substansi materi pembahasannya adalah nilai dari sebuah kesadaran. Kesadaran bela nilai bela Negara. Sesuai dengan UndangNegara pada hakikatnya merupakan Undang Nomor 11 Tahun 2011 Pasal 35 Ayat kesediaan berbakti pada Negara dan 3 tentang kurikulum menyatakan bahwa berkorban demi membela Negara. Kesadaran kurikulum Perguruan Tinggi dikembangkan bela Negara dibangun sebagai bagian dari oleh setiap Perguruan Tinggi dengan sistem pertahanan Negara. Oleh sebab itu mengacu pada Permenristekdikiti No 44 pertahanan Negara dilaksanakan oleh Tahun 2015 tentang standar nasional pemerintah dan dipersiapkan secara dini Pendidikan Tinggi wajib memuat mata kuliah dengan sistem pertahanan semesta yang Agama, Pancasila, Pendidikan melibatkan seluruh warga Negara, wilayah Kewarganegaraan, dan Bahasa Indonesia dan sumber daya nasional lainnya. Upaya yang merupakan satu kesatuan yang tidak bela Negara selain sebagai kewajiban dasar dapat dipisahkan (Kemenristekdikti, 2016). juga merupakan kehormatan bagi setiap Melalui pembahasan nilai nilai bela warga Negara yang dilaksanakan dengan Negara ini lah, pihak Universitas PGRI penuh kesadaran, tanggung jawab dan rela Palembang berupaya untuk memberikan berkorban dalam pengabdian kepada Negara pemahaman kepada mahasiswa bahwa upaya dan bangsa. Sebagai warga Negara sudah menjaga kesatuan Negara Repubik Indonesia sepantasnya ikut serta dalam bela Negara adalah tanggungjawab segenap warga Negara sebagai bentuk kecintaan kita kepada pada serta mewujudkan nilai nilai bela Negara Negara dan bangsa. Pertahanan semesta tidak dalam kehidupan nyata dengan meningkatkan akan dapat dimobilisasi jika warga Negara semangat berprestasi untuk mengharumkan yang menjadi sentral bergeraknya sistem nama bangsa dan memiliki sikap kritis, tidak memiliki sifat dan perilaku yang dijiwai keuletan dan loyalitas terhadap pekerjaannya. oleh kesadaran bela Negara.

Sebagaimana yang dikemukakan oleh

Universitas PGRI Palembang sebagai Noor (2016) bahwa pendidikan bela Negara Universitas yang telah terakreditasi dan salah merupakan bagian dari pendidikan karakter satu Universitas swasta terbaik di Kota atau penanaman budi pekerti. Dalam kondisi Palembang, berusaha untuk saat ini bela Negara harus diartikan lebih mengimplemetasikan nilai nilai bela Negara nyata. Bela negara tidak hanya diidentikkan kedalam program perkuliahan melalui mata dengan angkat senjata, tetapi harus diartikan 
lebih luas, yaitu membela Negara dalam to God Almighty, noble, healthy, berbagai hal disesuaikan dengan kemampuan knowledgeable, skilled, creative, independent, dan profesi masing-masing. Ikut and become citizens of a democratic and mengharumkan nama bangsa melalui prestasi accountable". Ahmad dkk (2017) juga dalam berbagai bidang juga termasuk bela mengungkapakan tujuan pendidikan nasional Negara. Jenderal Gatot Nurmantyo berkaitan dengan pembentukan karakter mendorong agar dunia Pendidikan Tinggi peserta didik sehingga mampu bersaing, memahami betul penerapan pendidikan bela beretika, bermoral, sopan santun dalam Negara tersebut dan menjabarkannya ke berinteraksi dengan masyarakat.

dalam fokus Pendidikan Tinggi secara umum dan pendidikan bela Negara secara khusus. METODE PENELITIAN Strategi bela Negara di Perguruan Tinggi Pendekatan penelitian yang digunakan mengajak pendidikan tinggi untuk berefleksi dalam penelitian ini adalah pendekatan dan menentukan konsep komprehensif yang kualitatif. Cresswel (2016) mengemukakan bisa dan akan dilakukan, agar pendidikan bela bahwa qualitative research is an inquiry Negara, benar-benar memberikan sesuatu process of understanding based on distinct yang berguna bagi rakyat (Gredinant, 2017). methological traditions of inquiry that

Akhirnya, bela Negara dan kebijakan explorea social or human problem. The pertahanan dimaksudkan untuk memberikan researcher build a complex, holistic picture, gambaran tentang hal-hal yang mendasar analysis words, reports detailed views of mengenai bela Negara dan kebijakan informants, and conducts the study in a pertahanan dan bertujuan untuk membekali natural setting. Pendapat tersebut masyarakat dengan nilai-nilai bela Negara menjelaskan bahwa penelitian kualitatif dan kebijakan pertahanan dalam rangka didasarkan pada tradisi metodologi penelitian membentuk karakter bangsa yang ulet dengan cara menyelidiki masalah sosial atau tangguh, berwawasan kebangsaan dan kemanusiaan. Oleh karena itu, melalui memiliki kesadaran bela Negara sebagai pendekatan ini, peneliti ingin mengetahui prasyarat dalam membangun sistem secara langsung upaya penanaman nilai nilai pertahanan semesta (Kementerian Ketahanan, bela Negara melalui mata kuliah pendidikan 2016). Selain itu Kristiawan (2015) juga Pancasila yang dilaksanakan di Universitas menyebutkan bahwa the purpose of education PGRI Palembang. is "... to be a man who is faithful and devoted 
Metode penelitian dalam penelitian belum memiliki sikap kritis terhadap ini menggunakan metode studi kasus. Yin permasalahan permasalahan yang ada di (2014) mengemukakan bahwa studi kasus sekitar mereka. Selain itu, mahasiswa juga adalah suatu inkuiri empiris yang menyelidiki masih belum memiliki semangat berprestasi fenomena di dalam konteks kehidupan nyata yang tinggi, hal ini terlihat dari kurangnya bilamana batas-batas antara fenomena dan kemampuan dasar mahasiswa dalam menulis konteks tak tampak dengan tegas, dan baik itu menulis makalah maupun menulis bilamana multisumber bukti dimanfaatkan. artikel ilmiah, selain itu, mahasiswa sering Penelitian ini dilakukan secara intensif, mengeluh terhadap tugas kuliah yang terperinci dan mendalam terhadap upaya diberikan kepada mahasiswa, ada yang penanaman nilai nilai bela Negara melalui beranggapan bahwa tugasnya terlalu banyak, Pendidikan Pancasila di Universitas PGRI ada juga yang beranggapan bahwa yang tugas Palembang. Teknik pengumpulan data di yang diberikan tidak perlu terlalu baik yang dalam penelitian ini menggunakan teknik penting mereka melaksanakan tugas yang wawancara, dokumentasi, dan observasi dan diberikan kepada mereka. Selain itu, kajian literarur literatur yang berkaitan kurangnya mahasiswa melakukan kunjungan dengan penelitian ini. Data dianalisis dengan ke perpustakaan baik fakultas maupun teknik analisis kualitatif yang bergerak secara universitas, kurang aktifnya organisasi interaktif terus-menerus antara pengumpulan kemahasiswaan menjadi indikator bahwa data, reduksi data, penyajian data, dan mahasiswa masih belum memiliki semangat kesimpulan. berprestasi. (Hasil Observasi dan Wawancara Pada Tanggal 13 - 15 Oktober 2017).

\section{HASIL PENELITIAN DAN} PEMBAHASAN
Dari kondisi ini, maka penanaman nilai nilai bela Negara di nilai sangat perlu

Dari hasil observasi dan wawancara untuk diterapkan kepada mahasiswa yang dilakukan oleh peneliti kepada beberapa Universitas PGRI Palembang, selain untuk mahasiswa Universitas PGRI Palembang dari menanamkan nilai nilai nasionalisme kepada berbagai program studi, peneliti mahasiswa, penanaman nilai nilai bela menyimpulkan bahwa mahasiswa Universitas Negara juga bertujuan agar mahasiswa PGRI Palembang masih belum memiliki memiliki sikap kritis dan semangat berpestasi pengetahuan yang luas tentang nilai nilai bela sebagai pencerminan nilai nilai bela Negara. Negara. Kemudian mahasiswa juga masih Penamanan nilai nilai bela Negara melalui 
pendidikan Pancasila di Universitas PGRI Sebagaimana yang dikemukakan oleh Palembang mencakup unsur unsur bela Durkhim (1990) bahwa pewarisan nilai-nilai Negara yaitu : (1) penanaman nilai nilai cinta kehidupan dilakukan melalui media tanah air, (1) penanaman nilai nilai kesadaran masyarakat dan melalui media pendidikan di berbangsa dan bernegara, (3) penanaman nilai sekolah. Keterikatan terhadap kelompok nilai keyakinan bahwa Pancasila sebagai sosial masyarakat dialami seseorang sejak ideologi bangsa, (4) penanaman nilai nilai kecil. Keterikatan diwaktu kecil berawal loyalitas kepada Negara, (5) penanaman nilai munculnya rasa empati berkembang menjadi nilai pengetahuan terhadap bela Negara, dan altruistik yaitu rasa ikhlas, tanpa pamrih (6) semangat berprestasi sebagai cerminan untuk bersikap empati terhadap benda dan dari cinta tanah air (Hasil Wawancara Pada berkembang terhadap lingkungannya.

Tanggal 10 Oktober 2017).

Kemudian Basrie (dalam Tim Abdi

Dalam upaya penanaman nilai nilai Guru, 2006) bahwa bela Negara merupakan bela Negara di Universitas PGRI Palembang, sikap, tekad, dan tindakan warga Negara yang pendekatan yang dilakukan oleh Universitas teratur, menyeluruh, terpadu dan berlanjut PGRI Palembang antara lain adalah dengan dilandasi oleh kecintaan pada tanah air, menanamkan nilai nilai sejarah bangsa kesadaran berbangsa dan bernegara kepada mahasiswa agar mahasiswa Indonesia, keyakinan dan kesaktian Pancasila mengetahui bahwa bangsa Indonesia sebagai ideologi Negara. Dalam Undangmerupakan bangsa yang memiliki nilai Undang Dasar 1945 pasal 17 ayat 3 yang sejarah yang kuat dan di isi oleh generasi berbunyi setiap warga Negara berhak dan terdahulu yang memiliki karakter yang kuat wajib ikut serta dalam upaya pembelaan hingga menjadikan bangsa Indonesia sebagai Negara. Dengan demikian setiap warga bangsa yang besar. Nilai-nilai positif dari Negara diharapkan untuk ikut berpartisipasi sejarah peristiwa masa lampau, perlu aktif dalam membela Negara.

ditanamkan kepada mahasiswa atau generasi Dalam upaya menanamkan nilai nilai penerus. Nilai bersifat dinamis, berubah bela Negara, Universitas PGRI Palembang sesuai perkembangan zaman yang terjadi. mengupayakan agar mahasiswa memahami Supaya nilai-nilai tetap terpelihara dari bahwa bela Negara bukan hanya diidentikan generasi ke generasi maka perlu adanya dengan mengangkat senjata, atau berperang proses internalisasi, proses revitalisasi dan melawan penjajah saja, akan tetapi, nilai nilai proses pemeliharaan secara terus-menerus. bela Negara dapat tercermin dari rasa 
nasionalisme yang tinggi, semangat Pendidikan Pancasila seharusnya menjadi ruh berprestasi, semangat menjaga kesatuan dalam membentuk jati diri mahasiswa dalam Republik Indonesia, dan semangat untuk mengembangkan jiwa profesionalisme berbenah menjadi pribadi yang lebih baik dan mereka sesuai dengan bidang studi masingdapat bermanfaat bagi kehidupan bangsa. masing.

Oleh karena itu, penanaman nilai nilai bela Sebagaimana yang dikemukakan Negara di Universitas PGRI Palembang di Wilber (1997) bahwa penanaman nilai bela nilai sangat diperlukan, dimana mahasiswa di Negara diharapkan dapat berdampak terus tiap Program Studi di lingkungan Universitas tertanam dan berkembang dengan baik dalam PGRI Palembang di nilai masih kurang jiwa siswa. Nilai dapat terpelihara dengan mempunyai motivasi tinggi dalam baik oleh individu apabila individu tersebut mengerjakan sesuatu, kurang berorganisasi, memiliki kesadaran yang baik terhadap nilaikurang berprestasi dan kurang ingin nilai. Kesadaran nilai akan terjaga apabila mengerjakan kegiatan yang menambah setiap individu telah mencapai kesadaran kompetensi. integral. Empat Quadrant manusia dalam

Oleh karena itu, penanaman nilai nilai kesadaran, yaitu intentional, behavioural, bela Negara dapat dijadikan alat untuk cultural, and social. Dari pengalaman indera, menanamkan nilai nilai nasionalisme kepada pengalaman kejiwaan, dan pengalaman mahasiswa, menuntut partisipasi mahasiswa religius akan muncul kesadaran diri. sebagai bagian dari warga Negara untuk kesadaran itu berlangsung dari mata secara mempertahankan kesatuan bangsa dan juga fisik (eye of flesh) menuju mata pikir (eye of dapat dijadikan sebagai sarana untuk mind) dan berakhir pada mata hati (eye of meningkatkan motivasi mahasiswa untuk contemplation). Kesadaran inilah yang berprestasi. Dengan adanya upaya penanaman dimaksud sebagai "Kesadaran Integral", nilai nilai bela Negara dalam mata kuliah yaitu kesadaran yang melibatkan seluruh pendidikan Pancasila, Universitas PGRI fungsi indra dan mental manusia .

Palembang mengharapkan agar mahasiswa Kemudian Noor memiliki kesadaran secara menyeluruh mengemukakan bahwa dalam kondisi saat ini (integral) yang tercermin melalui sikap kritis bela Negara harus diartikan lebih tindak lingkungan sekitarnya, semangat berprestasi nyata. Bela Negara tidak hanya diidentikkan yang tinggi, dan loyalitas terhadap Negara. dengan angkat senjata, tetapi harus diartikan Kemenristekdikti (2016) menyatakan bahwa lebih luas, yaitu membela negara dalam 
berbagai hal disesuaikan dengan kemampuan semangat berprestasi sebagai cerminan dari dan profesi masing-masing. Ikut cinta tanah air.

mengharumkan nama bangsa melalui prestasi Pendekatan yang dilakukan dalam dalam berbagai bidang juga termasuk bela upaya penanaman nilai nilai bela Negara di Negara. Kemudian upaya bela Negara wajib Universitas PGRI Palembang dengan dilakukan dalam kerangka pembinaan pendekatan sejarah bangsa. Penanaman nilai kesadaran bela Negara sebagai sebuah upaya nilai bela Negara di Universitas PGRI untuk mewujudkan WNI yang memahami Palembang lebih memprioritaskan untuk dan menghayati serta yakin untuk mengembangkan sifat aktif mahasiswa yang menunaikan hak dan kewajibannya. Bangsa pada akhirnya mahasiswa mampu Indonesia ingin pula mempunyai peradaban meningkatkan rasa cinta tanah air dan bangsa yang unggul dan mulia. Peradaban demikian melalui penanaman nilai nilai bela Negara dapat dicapai apabila masyarakat dan bangsa yang tercermin dalam yang tercermin melalui kita juga adalah masyarakat dan bangsa baik sikap kritis lingkungan sekitarnya, semangat (good society and nation), damai, adil dan berprestasi yang tinggi, dan loyalitas terhadap sejahtera, sebagaimana yang telah Negara.

diwasiatkan oleh para pendiri bangsa (founding fathers) dalam Pembukaan UUD DAFTAR PUSTAKA 1945 (Kementerian Pertahanan, 2016).

Ahmad, S., Kristiawan, M., Tobari, T., \& Suhono, S. (2017). Desain Pembelajaran SMA Plus Negeri 2

\section{KESIMPULAN}

Penamanan nilai nilai bela Negara melalui Pendidikan Pancasila di Universitas PGRI Palembang mencakup (1) penanaman nilai nilai cinta tanah air, (1) penanaman nilai nilai kesadaran berbangsa dan bernegara, (3) penanaman nilai nilai keyakinan bahwa $\mathrm{C}$ Pancasila sebagai ideologi bangsa, (4) penanaman nilai nilai loyalitas kepada Negara, (5) penanaman nilai nilai pengetahuan terhadap bela Negara, dan (6)
Banyuasin III Berbasis Karakter Di Era Masyarakat Ekonomi ASEAN. Iqra (Educational Journal), 2(2), 403-432.

Anwar, Raffi. (2011). Kesadaran Bela Negara.

http://hankam.kompasiana.com/2011/08 /15/kesadaran-bela-negara 388384.

Creswell, J. (2016). Research Design. Yogyakarta: Pustaka Pelajar.

Durkheim, E. (1990). Pendidikan Moral, Suatu Studi Teori Dan Aplikasi Sosiologi Pendidikan. (Judul asli: Moral Edu-cation: 1961). Jakarta: Erlangga. 
Friedman, George. (2009). The Next 100 Years : A Forecast for the 11St Century. New York: Anchor Book.

Gredinant, Dony. (2017). Application Of Tim State Defense Education In Colleges. Jurnal Prodi Strategi Pertahanan Darat Volume 3 Nomor 1: 1-17.

Hadi, Y, Suryo, D, Sudarsono (2014). Dinamika Penanaman Nilai-Nilai Bela Negara Kadet Maguwo Dalam Perspektif Historis. Jurnal Pembangunan Pendidikan: Fondasi dan Aplikasi Volume 1, Nomor 1: 110111.

Kementerian Pertahanan Republik Indonesia. (2016). Wira. Kemenhan.go.id.

Kemenristekdikti. (2016). Pendidikan Pancasila Untuk Perguruan Tinggi. Jakarta: Kemenristekdikti.

Kristiawan, M. (2015). A Model of Educational Character in High School Al-Istiqamah Simpang Empat, West Pasaman, West Sumatera. Research Journal of Education, 1(2), 15-20.

Kristiawan, M. (2016). Telaah Revolusi Mental dan Pendidikan Karakter dalam Pembentukkan Sumber Daya Manusia Indonesia Yang Pandai dan Berakhlak Mulia. Ta'dib, 18(1), 13-25.

Mahifal (2016). Membangun Keutuhan Negara Kesatuan Republik Indonesia melalui pembinaan ideologi dan wawasan kebangsaan. Jurnal Pedagogia FKIP-Unpak.

Noor. Ady Ferdian. (2016). Pendidikan Kewarganegaraan Melalui Program Bela Negara: Perspektif Mahasiswa Mencintai Tanah Air Dan Bangsa (Studi Kasus Mahasiswa Program Studi PGSD Universitas Muhammadiyah
Palangkaraya). Pedagogik Jurnal Pendidikan, Volume 11 Nomor $1: 1$ 8.

Abdi Guru. 2006. Pendidikan Kewarganegaraan. Jakarta: Erlanggga.

Wardana, Andrie K. (2009). Aspek - Aspek Bela Negara. http://nationfortressonline.blogspot.com /search/label/Bela\%10Negara.

Wilber, K. (1997). An Integral theory of conciousness .Journal of Conciousness Studies. Imprint Academic.

Yin, Robert, K. (2014). Studi Kasus, Desain dan Metode. Jakarta: Raja Grafindo Persada. 
JMKSP

Jurnal Manajemen, Kepemimpinan, dan Supervisi 